\title{
Periádica Eletrânica

\section{GEOTECNOLOGIAS APLICADAS NA ESPACIALIZAÇÃO DAS APP E DE CONFLITOS NA MICROBACIA DO CÓRREGO DO PRELÚDIO - ITAPEVA/SP}

\author{
Sérgio Campos ${ }^{1}$ \\ Andressa Oliveira Fernandes ${ }^{2}$ \\ Marcelo Campos ${ }^{3}$
}

\begin{abstract}
RESUMO
O presente trabalho teve como objetivo analisar os diferentes tipos de uso e ocupação do solo e de conflito em Áreas de Preservação Permanente (APP) da microbacia do córrego do Prelúdio localizada no município de Itapeva, São Paulo, apresentando uma área de 874,46ha. A base cartográfica utilizada foram a carta planialtimétrica (IBGE, 1974) e a imagem de satélite utilizada foi do Landsat-8 datada de novembro de 2013, órbita 222, ponto 77 . Para tomada de decisões utilizou-se do Sistema de Informação Geográfica (SIG) - Idrisi Selva e o software CartaLinx. O trabalho teve como base a Lei Florestal no 12.651/12 com alterações feitas pela Lei Federal oㅜ 12.727/12. A microbacia do córrego do Prelúdio apresentou como classes de uso e ocupação do solo, a cultura com 91,91ha $(10,51 \%)$, represa 26,52 ha $(3,03 \%)$, mata ciliar 223,27 ha $(25,53 \%)$, solo preparado 529,74 ha $(60,58 \%)$ e mata $3,02 \mathrm{ha}(0,34 \%)$. Os usos conflitantes em APP foram a classe de uso de solo preparado, embora, grande parte das APP estar de acordo com a Lei, o uso de solo preparado vêm conflitando $26,02 \%$ desta. Os SIG mostraram-se apropriados para o estudo como na elaboração dos mapas e suporte nas futuras aplicações de projetos na região.
\end{abstract}

Palavras-Chave: Bacia Hidrográfica; Lei Florestal; Uso e Ocupação; Sistemas de Informação Geográfica

\section{GEOTECHNOLOGIES APPLIED SPATIALIZACION OF PPA AND CONFLICT IN THE STREAM PRELUDIO WATERSHED - ITAPEVA / SP}

\begin{abstract}
\footnotetext{
${ }^{1}$ Prof. Titular, Departamento de Engenharia Rural, Faculdade de Ciências

Agronômicas/UNESP.seca@fca.unesp.br.

2 Prof. Dr., EDUVALE - Avaré. rcnardini@yahoo.com.

${ }^{3}$ Prof. Dr., Faculdade de Ciências Agronômicas/UNESP.seca@fca.unesp.br.
}

This study aimed to analyze the different types of land use and occupation and conflict in Permanent Preservation Areas (APP) Prelude Stream watershed in the municipality of Itapeva, São Paulo, with an area of 874.46 ha. The cartographic base used were the planialtimetric letter (IBGE, 1974) and the satellite image was used Landsat-8 dated November 2013, orbit 222, paragraph 77. For decisionmaking used is the Geographic Information System (GIS ) - Idrisi Selva and the CartaLinx software. The work was based on the Forestry Law No. 12.651/12 with changes made by Federal Law No. 12,727 / 12. The Prelude Stream watershed presented as classes use and occupation of land, the culture with $91.91 \mathrm{ha}(10.51 \%)$, dam $26.52 \mathrm{ha}(3.03 \%)$, riparian $223.27 \mathrm{ha}(25.53 \%)$, prepared soil 529.74ha $(60.58 \%)$ and kills $3.02 \mathrm{ha}(0.34 \%)$. The conflicting uses in APP were prepared land use class, though, much of the APP comply with the law, the use of prepared soil are conflicting $26.02 \%$ of 


\section{Periódica Eletranica

this. GIS proved to be suitable for the study as in mapping and support for future project applications in the region.

Keywords: Watershed; Forestry Law; Use and occupation; Geographic Information Systems

\section{INTRODUÇÃO}

Atualmente o crescimento desordenado e acelerado das cidades é causado pela explosão demográfica e grande êxodo rural. O processo de urbanização está relacionado com possíveis mudanças na paisagem, cobertura e uso da terra, desencadeando alterações ao meio ambiente (PIMENTEL et al., 2012) .

Como vimos, a sociedade está em constante evolução, devido a isso, a pressão sobre os recursos naturais vem se agravando no que implica a busca de conhecimentos avançados sobre ferramentas tecnológicas que apresentem resultados rápidos e que facilitem o trabalho. Frente a isso, podemos analisar 0 geoprocessamento que possui um conjunto de técnicas que se destacam em meio aos estudos ambientais, pesquisas, planejamento, manejo, processos de gestão e em vários outros aspectos.

O geoprocessamento representa qualquer tipo de processamento de dados georreferenciados. Para ROSA (2005), também conhecidas como "geoprocessamento", as geotecnologias são o conjunto de tecnologias para coleta, processamento, análise e oferta de informações com referência geográfica. As geotecnologias são compostas por soluções em hardware, software e peopleware que juntos constituem poderosas ferramentas para tomada de decisões.

Desta forma, dentre as geotecnologias podemos destacar: Sistemas de Informação Geográfica (SIG), cartografia digital, sensoriamento remoto, Sistema de Posicionamento Global e a topografia que compreendem a geotecnologia.

O uso do SIG tem se tornado cada vez mais utilizados no planejamento do uso do solo, por se tratar de ferramentas com alta capacidade de armazenamento de informações bem como a grande capacidade de manipulação dos dados armazenados. Sua utilização tem representado uma maior rapidez e eficácia em regiões de microbacias, gerando mapas que auxiliam no estudo e no planejamento dessas áreas (NARDINI, 2009). 


\section{Periódica Eletrânica

Relacionado a isso, tem-se como um dos temas mais abordados na atualidade, a questão ambiental. E, nos últimos anos, destacou-se os debates quanto a preservação ambiental, tendo como enfoque principal o Código Florestal.

Pode-se afirmar quanto a legislação ambiental que nenhuma outra provocou tamanha repercussão no Brasil como o Código Florestal ou Lei Florestal. Lei esta que regula as relações entre conservação dos recursos naturais e produção agrícola abrangendo assim, questões socioambientais, políticas, econômicas, de interesse de diversas áreas e, principalmente de interesse nacional (GARCIA, 2014).

O conhecimento sobre essa legislação ambiental é de extrema importância, tendo como base a Lei $n^{0}$ 12.651/12 com alterações feitas pela Lei Federal ํo 12.727/12 que estabelece regras no que diz respeito á áreas que precisam ser recuperadas e preservadas.

Conhecida como a "capital dos minérios" o município de Itapeva está localizado no estado de São Paulo, possui como economia suporte a mineração, agricultura e a indústria, sua população é de 87.765 habitantes e atualmente é o terceiro no Estado em extensão territorial.

A microbacia do córrego do Prelúdio localizada em Itapeva (SP) mais precisamente na sua área rural, possui aproximadamente $874,46 \mathrm{ha}$ e sua predominância é de culturas agrícolas. O local da área definido deve-se ao fato da carência em estudos relacionados à legislação ambiental e a ausência de conhecimento sobre preservação e conservação, buscando assim contribuir com planejamentos engajados ao meio ambiental e consequentemente a qualidade de vida do município.

Este trabalho tem como objetivos, a identificação e análise do uso e ocupação do solo na microbacia do córrego do Prelúdio e das Áreas de Preservação Permanente (APP) e seus conflitos de uso ao longo do córrego presente na bacia hidrográfica em estudo tendo como base a legislação ambiental vigente e fazendo uso do SIG - Idrisi e do software CartaLinx. Ao final, pretende propor medidas para um futuro planejamento ambiental visando a conservação e preservação dos recursos hídricos. 


\section{Periódica Eletranica

\section{MATERIAL E MÉTODOS}

O município de Itapeva, interior do estado de São Paulo, está ainda em fase de evolução, mas é devidamente conhecida como a "capital dos minérios" possuindo como economia suporte a mineração, agricultura e a indústria, sendo o segundo maior produtor estadual de Tomate oferecendo também grandes lavouras de milho, soja e feijão, sua população total são de 87.765 habitantes e atualmente é o terceiro no Estado em extensão territorial. A cidade tem como municípios limítrofes Itaberá, Itararé, Nova Campina, Taquarivaí e Guapiara.

O clima de Itapeva é classificado de acordo com a Classificação Climática de Köppen como "CWa", sendo que a temperatura média varia entre a mínima de 9,4ํㅡ e máxima de $22,9^{\circ} \mathrm{C}$ e sua precipitação média anual é de $50,7 \mathrm{~mm}$ segundo o Centro de Pesquisas Meteorológicas e Climáticas Aplicadas a Agricultura (CEPAGRI).

A microbacia hidrográfica do córrego do Prelúdio (Figura 1) apresenta uma área de 874,46 hectares, situada entre a coordenadas geográficas $23^{\circ} 37^{\prime} 22^{\prime \prime}$ e $23^{\circ}$ 39' 31" de latitude Sul e 48 33' 02" e 48 35' 03" de longitude W GR.

O Estado de São Paulo é dividido em 22 Unidades de Gerenciamento de Recursos Hídricos (UGRHI), nas quais atuam 21 Comitês de Bacias Hidrográficas (CBH). Assim, a microbacia hidrográfica do córrego do Prelúdio pertence a UGRHI 14, que corresponde a Bacia Hidrográfica do Alto do Paranapanema. Essas divisões foram feitas com base no ponto de vista hidrológico, onde a adoção da bacia hidrográfica tem elo de ligação entre municípios, assumida como unidade de gestão dos recursos hídricos. 
Figura 1. Localização da microbacia do Córrego do Prelúdio, Itapeva/SP.

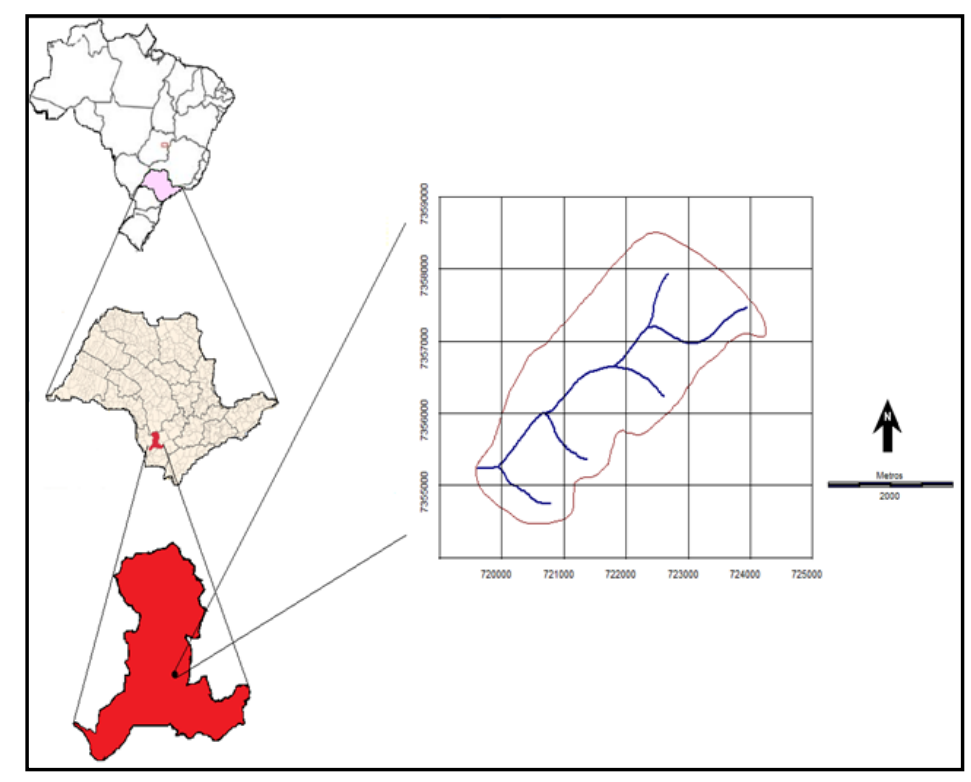

Essas unidades tratam sobre a preservação e conservação dos recursos hídricos e garantem a qualidade de água nos municípios.

Para o apoio cartográfico, utilizou-se a carta planialtimétrica em formato digital, editada pelo Instituto Brasileiro de Geografia e Estatística - IBGE (1973) referente a folha de Itapeva (SF-22-Z-D-V-3) sendo o sistema de referência o Córrego Alegre (antigo datum planimétrico brasileiro), em escala 1:50.000 com equidistância das curvas de nível de 20 metros onde obteve-se os pontos de controle (coordenadas) para o georreferenciamento e a altimetria para digitalização do limite da bacia hidrográfica.

Os pontos de controle são locais que oferecem uma feição física perfeitamente identificável, tais como intersecções de estradas e de rios, represas, pistas de aeroportos, edifícios proeminentes, topos de montanha, dentre outros (ROQUE et al., 2006).

A imagem de satélite utilizada foi do Landsat - 8, sensor OLI (Operational Land Imager), de novembro de 2013 , órbita 222 , ponto 77 , com resolução espacial de $30 \times 30$ metros, operando em sete bandas espectrais das quais, para este trabalho, utilizaram-se três bandas (6, 5 e 4), pois estas apresentam uma melhor visualização na discriminação dos alvos. As imagens foram obtidas no catálogo de imagens do Departamento do Interior dos EUA/ Pesquisa Geológica. 


\section{Periádica Eletranica

O Sistema de Informações Geográficas - IDRISI Selva foi usado no processamento das informações, georreferenciamento, composição colorida da imagem de satélite - bandas 6, 5 e 4 em RGB (Red Green Blue) -, conversão dos dados de vetoriais para raster, elaboração dos mapas de uso e ocupação do solo, geração dos buffers de APP e os conflitos de uso.

O software CartaLinx, desenvolvido pela Clark University, se aplica à construção de base de dados relacionais na forma de pontos, linhas e polígonos. Trabalha com formatos de arquivos do IDRISI e de outros softwares. Estes dados são tipicamente exportados para um SIG em coberturas (GIANUCA e TAGLIANI, 2012).

Desta forma, este software foi utilizado na digitalização do limite da área de estudo e rede de drenagem obtidos da carta planialtimétrica e as áreas de cobertura vegetal nas imagens de satélite.

Utilizou-se também o Google Earth para auxiliar na interpretação visual de algumas áreas - já que as imagens disponíveis são de alta resolução. Segundo BROWN (2006), o Google Earth é um aplicativo cliente-servidor para desktop que possibilita a visualização de imagens de sensores acoplados em satélites em um ambiente dinâmico, permitindo visualizações em duas e três dimensões, tornando possível a interatividade do usuário.

A primeira etapa consistiu no georreferenciamento da carta planialtimétrica do IBGE no qual foi realizado no IDRISI no menu Reformat/Resample onde em Input utilizou o arquivo a ser georreferenciado.

Para ROQUE et al. (2206), georreferenciar uma imagem ou mapa é tornar suas coordenadas conhecidas num dado sistema de referência, tal processo iniciase com a obtenção das coordenadas (pertencentes ao sistema no qual se planeja georreferenciar) de pontos da imagem ou do mapa a serem georreferenciados, conhecidos como Pontos de Controle.

Após o georreferenciamento, efetuou-se o recorte da área a ser estudada na opção Reformat/Window.

Em seguida, esse arquivo foi exportado para o software CartaLinx comando File/lmage Conversions e posteriormente começou-se a delimitar os elementos (coverages) - limite e rede de drenagem - sendo que, para o limite foi criado polígono, enquanto que, para a rede de drenagem, linhas. Uma coverage 


\section{Periádica Eletranica

representa uma coleção de feições geográficas e seus atributos (HAGAN et al., 1998).

A primeira etapa, com a utilização de imagem de satélite, foi georreferenciar as bandas 6, 5 e 4, utilizando o módulo Reformat/ Resample do IDRISI. Como base, usou-se a carta planialtimétrica do IBGE, georreferenciada, no qual os pontos de controle para o georreferenciamento foram escolhidos em pontos homólogos.

Foram utilizados 10 pontos de controle, sendo que é necessário um número mínimo para que o SIG possa efetuar as operações matemáticas para a georreferência. Esses pontos são feições homólogas facilmente identificáveis (confluência de rios, cruzamento de estradas, etc.) tanto na imagem a ser georreferenciada quanto na que apresenta um sistema de referência (cartas topográficas, mapas digitais, etc.).

Por isso, é essencial que os pontos de controles estejam bem distribuídos ao longo da imagem uma vez que o ajuste e a equação do SIG é feito com base nesta distribuição.

Tendo como base o exposto por EASTMAN (1998), após a definição dos pontos de controle, deve-se observar o erro médio quadrático (RMS) e o resíduo de erro individual de cada ponto de controle. Esses resíduos expressam quanto cada ponto de controle se desvia da equação de melhor ajuste e é por isso que um ponto com resíduo alto sugere que as coordenadas de ponto foram mal escolhidas. $O$ RMS total descreve o erro de posicionamento de todos os pontos de controle em relação à equação.

Após o georreferenciamento, efetuou-se o recorte da imagem através da opção Reformat/Window extraindo assim apenas a área da bacia.

Com as bandas das imagens georreferenciadas, foi realizado o processo de composição da imagem RGB (Red, Green, Blue), utilizando-se da função Composite do menu Display do IDRISI (Figura 2).

Segundo FIGUEIREDO (2005) a composição é fundamental para uma boa identificação e discriminação dos alvos terrestres já que o olho humano é capaz de discriminar mais facilmente matizes de cores do que tons de cinza. A composição colorida trata-se de um dos artifícios de maior utilidade na interpretação das informações do Sensoriamento Remoto. 


\section{Fórum Ambiental}

da Alta Paulista

Figura 2. Carta imagem da microbacia do Córrego do Prelúdio, Itapeva/SP.

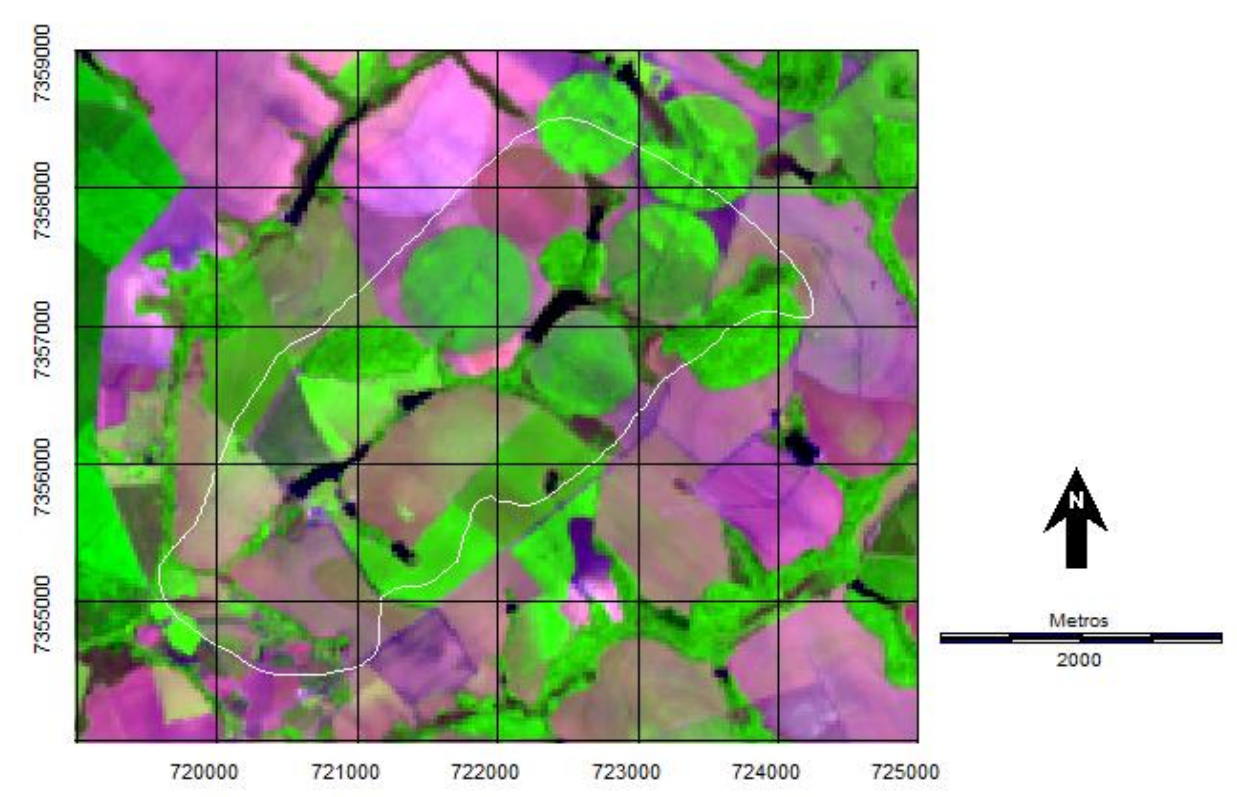

Após o recorte, no software CartaLinx foi realizada a interpretação visual em tela, onde as áreas de uso e ocupação foram classificadas sobre a composição colorida, ampliadas em tela para melhor visualização.

Para a elaboração dos polígonos de uso e cobertura, criou-se uma tabela, no menu Tables/Add Fields e em cada polígono no comando polígono locator e feature properties colocou-se o número (código) correspondente a classe de uso (ex: Mata Ciliar =1, Mata =2, Pastagem = 3, e assim sucessivamente) .

Em seguida, foi exportado para o IDRISI e transformado para o formato raster (matriz digital de linha e colunas) e na sequência, no comando Area do menu Database Query, pertencente ao módulo Analysis, foram determinadas as áreas e as porcentagens de cada uso.

Definiram-se as Áreas de Preservação Permanente ao longo dos cursos d'água e ao redor das nascentes da microbacia do córrego do Prelúdio. Os buffers foram criados no menu GIS Analysis, ferramenta Distance Operators - Buffer. Para isso, foi necessário repetir esse passo duas vezes, sendo uma para os cursos d'água e o outro para a nascente.

Assim, proporcionou a criação de um raio de 50 metros circulando as áreas das nascentes e um buffer de 30 metros de cada lado da margem na drenagem ao longo do leito do córrego (medidas estas estipuladas, já que a largura dos cursos d'água presentes na área estudada são inferiores a 10 metros) resultando na delimitação das APPs. 


\section{Periádica Eletranica

Em seguida, foi realizada a junção dos buffer na ferramenta de álgebra de mapas. Através do menu GIS Analysis, ferramenta Mathematical Operators OVERLAY escolheu-se os dois buffers gerados anteriormente e em Overlay options selecionou-se a opção matemática First + Second.

Segundo ROSA (2011), o processo de representar esquematicamente um modelo é realizado pela álgebra de mapas, que consiste numa forma de organizar os métodos dos quais as variáveis e as operações vão desenvolver o modelo. Os conceitos da álgebra de mapas são semelhantes aos da matemática, ou seja, seguem uma lógica e uma terminologia da qual se compõem esquemas ou equações, sendo que estas equações podem ser simples ou complexas. Paralelamente aos operadores matemáticos (soma, subtração, multiplicação e divisão), também se usam operadores lógicos para representar as relações entre variáveis ou as combinações entre mapas.

Posteriormente, foi preciso juntar as feições já que os atributos das áreas comuns aos dois arquivos foram somados, de maneira que um novo atributo surgiu e no caso, é preciso que toda APP tenha o mesmo identificador, por isso, fez-se a reclassificação no menu GIS Analysis ferramenta Distance Operators - RECLASS. Para sua execução, em Type of file to reclas marcou a opção Image e em Classification type, User-defined reclass. Escolheu o arquivo gerado anteriormente e em Reclass parameters - Assign a new value of colocou-se os novos valores e em To all values from e To Just less than, os antigos.

O termo buffer é definido para TEIXEIRA e CHRISTOFOLETTI (1997) em ambiente SIG, como uma forma de análise de proximidade onde zonas de uma determinada dimensão são delimitadas em volta de uma feição ou de um elemento geográfico, levando-se em conta um determinado atributo.

Para identificar as áreas de conflitos de uso do solo em Áreas de Preservação Permanentes, utilizou-se a álgebra de mapas realizando uma sobreposição do mapa de uso e ocupação do solo com o mapa das APPs.

Os procedimentos foram executados no IDRISI utilizando-se a ferramenta Mathematical Operators - Overlay do menu GIS Analysis e selecionou-se a opção matemática First $x$ Second, operação essa que pode também ser denominada de sobreposição. 
A sobreposição implica que as camadas (layers) sobrepostas pertençam à mesma área e se encontre no mesmo sistema de coordenadas e na mesma projeção cartográfica. A sobreposição permite observar a existência (ou não) de relação entre fenômenos diferentes que se manifestam na mesma área geográfica. A sobreposição permite identificar padrões de distribuição de fenômenos e de estabelecer relações entre eles, sendo um dos principais objetivos da análise espacial (ROSA, 2011).

Após a sobreposição desses mapas, as áreas de ocorrência dos conflitos de acordo com as classes de uso foram devidamente quantificadas, executando as funções de cálculo de área, pela ferramenta Area do menu Database Query, pertencente ao módulo Analysis do IDRISI.

Foram consideradas sob uso conflitante as áreas cultivadas e ocupadas com outros fins presentes nas APPs das nascentes e cursos d'água.

\section{RESULTADOS E DISCUSSÃO}

O município de Itapeva possui grandes lavouras que são produzidas pela maioria por pequenos produtores os quais participam efetivamente da economia da cidade. Sendo assim, como o solo é usado para beneficiamento da população, é dever mantê-lo de forma sustentável para que o mesmo seja enriquecido e usado posteriormente.

A microbacia do córrego do Prelúdio (Figura 3 e Tabela 1) permitiu constatar como resultado do estudo de uso e ocupação do solo que foi feito por meio de imagem de satélite e posteriormente visita ao local, o total de 5 classes de uso.

Os valores foram obtidos permitiram quantificar o solo preparado, com maior valor de ocupação, com 529,74ha (60,58\%), seguido pela mata ciliar com 223,27 ha $(25,53 \%)$; cultura correspondendo a 91,91 ha $(10,51 \%)$; represa com 26,52 ha $(3,03 \%)$ e mata representado por $3,02 \mathrm{ha}(0,34 \%)$. 
Figura 3. Uso e Ocupação do Solo da microbacia do Córrego do Prelúdio, Itapeva/SP.

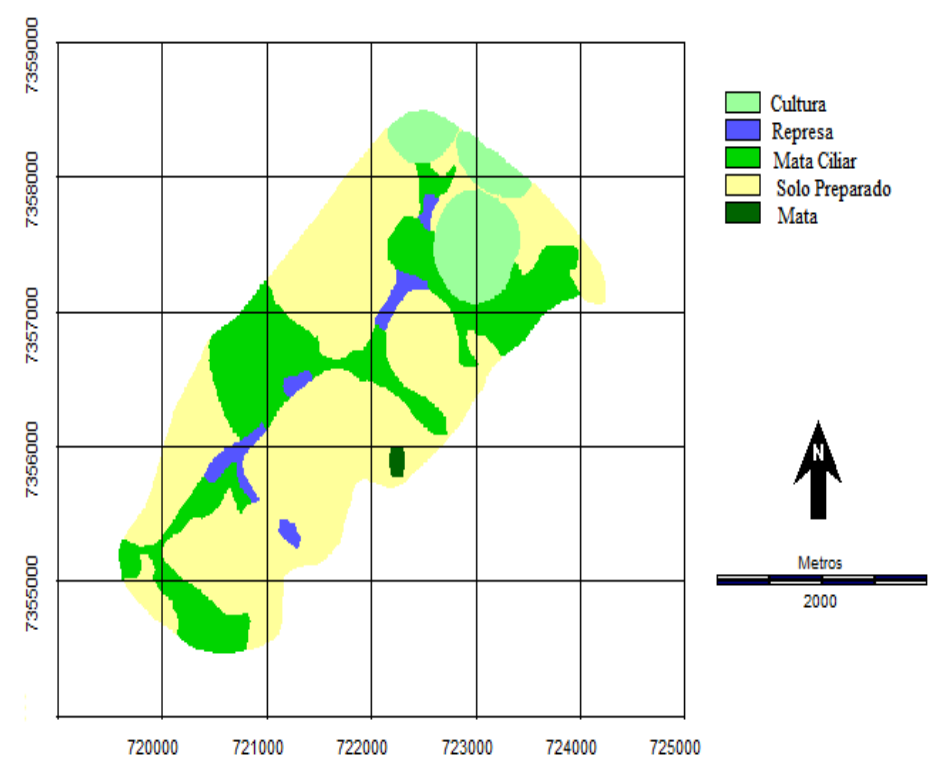

Tabela 1. Uso e ocupação do solo da microbacia do Córrego do Prelúdio, Itapeva/SP..

\begin{tabular}{|c|c|c|}
\hline \multirow[t]{2}{*}{ Classes de Uso e Ocupação do Solo } & \multicolumn{2}{|c|}{ Área } \\
\hline & (ha) & $\%$ \\
\hline Cultura & 91,91 & 10,51 \\
\hline Represa & 26,52 & 3,03 \\
\hline Mata Ciliar & 223,27 & 25,53 \\
\hline Solo Preparado & 529,74 & 60,58 \\
\hline Mata & 3,02 & 0,34 \\
\hline Total & 874,46 & 100 \\
\hline
\end{tabular}

A classe de solo preparado foi identificada pela imagem de satélite de novembro de 2013, ou seja, em época que não havia sido plantado nenhum tipo de cultura, mas com a visita a área, que foi realizada em 2014, encontrou a mesma área com o cultivo de soja (ainda em estágios iniciais de plantio) e também o cultivo de tomate, já em fase de colheita.

A microbacia do córrego do Prelúdio possui uma área total de preservação permanente relativa a 61,01 ha (Figura 4), dos quais 4,05 ha (6,63\%) são compostos por áreas de nascentes e 56,96ha (93,36\%) são áreas de preservação permanente ao longo dos cursos d'água. 
Figura 4. Áreas de Preservação Permanente da microbacia do córrego do Prelúdio, Itapeva - SP.

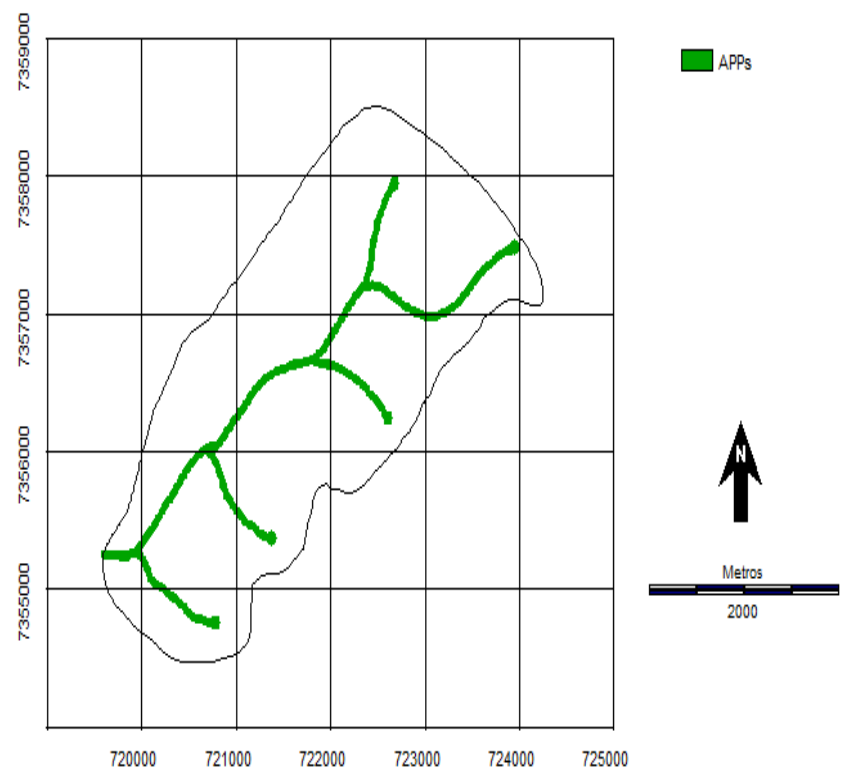

Segundo a legislação Florestal no 12.727, foi gerado o mapeamento das APP, considerando as nascentes num raio de 50 metros e para os cursos d'água 30 metros de cada lado da margem, a partir do leito regular do rio.

Conforme o estudo da legislação ambiental e os próprios conhecimentos adquiridos durante a graduação, vimos que a vegetação ao longo do curso d'água exerce papel fundamental numa microbacia como por exemplo, a diminuição de assoreamentos, preservação de biodiversidade, além da manutenção da água entre outros fatores.

Figura 5. Conflito de uso em APP da microbacia do córrego do Prelúdio, Itapeva - SP.

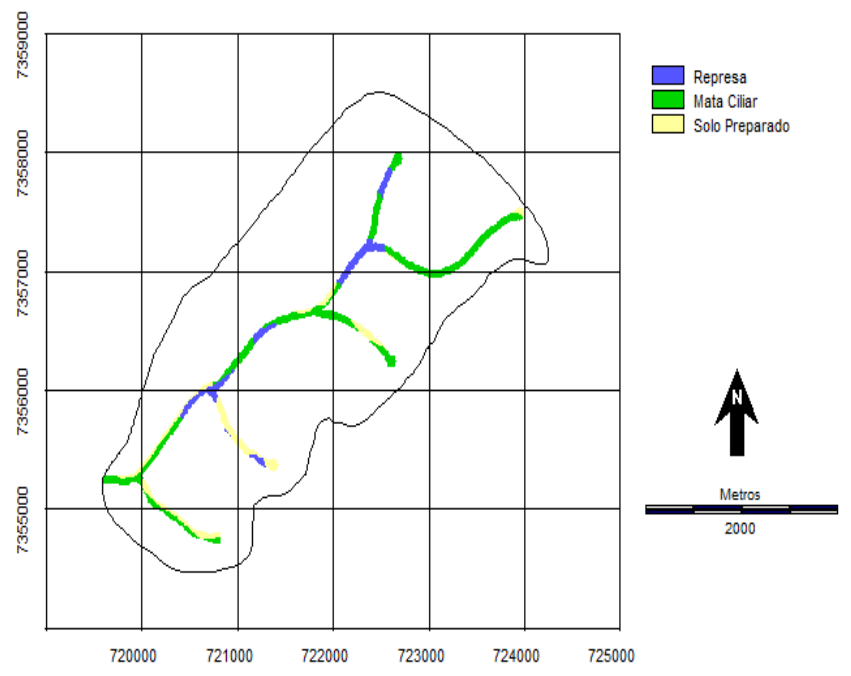


Tabela 2. Áreas de conflitos de uso do solo em APP.

\begin{tabular}{ccccc}
\hline Classes de uso da Terra & \multicolumn{2}{c}{ APP } & \multicolumn{2}{c}{ Conflitos } \\
\hline & ha & $\%$ & ha & $\%$ \\
Represa & 11,58 & 18,98 & - & - \\
Mata Ciliar & 33,45 & 54,82 & - & - \\
Solo Preparado & 15,88 & 26,02 & 15,88 & 100 \\
\hline Total & $\mathbf{6 1 , 0 1}$ & $\mathbf{1 0 0}$ & $\mathbf{1 5 , 8 8}$ & $\mathbf{1 0 0}$ \\
\hline
\end{tabular}

A mata ciliar quando conservada ao longo dos cursos d'água trazem muitos benefícios ao meio ambiente, no entanto as Áreas de Preservação Permanente estão sendo usadas inadequadamente, que mesmo sendo pouco ainda causam impactos e danos ao ambiente.

Assim, a classe de solo preparado correspondeu a 15,88ha de um total 61,01ha de APP da microbacia que deveriam estar apenas com vegetação natural, apresentam pontos de assoreamentos ao longo do curso d'água da microbacia do córrego do Prelúdio.

Assim, acredita-se que os agricultores ainda não foram devidamente informados ou omitem tal conhecimento, sobre a responsabilidade ambiental engajada as práticas agrícolas, seja ela direta ou indiretamente causada.

Frente a isso, cabe a Secretaria da Agricultura de Itapeva, organizar encontros entre produtores e pessoas capacitadas a respeito do Código Florestal, em especial ao Cadastro Ambiental Rural (CAR) que é uma obrigação de todos os proprietários rurais, entre outros eventos a fim de informar e conscientizar os produtores rurais. E, se trabalhado e colocados em prática de forma adequada, podem trazer mudanças e consequentemente melhorias ao Município.

\section{CONCLUSÕES}

O uso das Geotecnologias, como o Sistema de Informação Geográfica SIG Idrisi Selva, mostrou-se eficiente para análises ambientais do uso e ocupação do solo e de APP. A elaboração de mapas contribuiu para um maior entendimento e estudo das áreas conflitantes além da praticidade, por ser um programa de fácil utilização e aprendizado, o qual tem-se também o sensoriamento remoto por meio das imagens de satélite que pode ajudar no fator tempo para quem precisa ir a campo analisar frequentemente as mudanças das áreas trabalhadas. 


\section{Periódica Eletranica

A falta de estudos envolvidos sobre esta temática visando a conservação e preservação dos recursos hídricos no município de Itapeva/SP torna-se relevante já que assuntos como esses ganharam força no ultimo século e cada vez mais a interferência do homem está prejudicando a natureza e gerando consequências negativas para a comunidade.

Na microbacia do córrego do Prelúdio, a principal classe de uso e ocupação foi o solo preparado com 529,74 ha enfocando assim, sua participação agrícola para o município. Quanto aos usos conflitantes em APP, esta mesma classe foi a responsável, com 15,88ha de uso inadequado em APP.

Por fim, com base nos conhecimentos adquiridos durante a realização deste trabalho, destaca-se ainda que a utilização de ferramentas de geotecnologia é um mercado a ser muito explorado, pois não traz benefícios somente para a área florestal, agrícola, geográfica, climática, entre outras, mas também para todos os tipos de pesquisas, áreas, planejamentos e gerenciamentos.

\section{REFERÊNCIAS}

BROWN, M. C. Hacking Google Maps and Google Earth. Indianapolis: Wiley Publishing, Inc, 2006.

EASTMAN, J. R. IDRISI for Windows: Introdução e Exercícios tutoriais. Editores de versão em português, Heinrick Hasenack e Eliseu Weber. Porto Alegre, UFRGS: Centro de Recursos Idrisi, 1998.

FIGUEIREDO, D. Conceitos Básicos de Sensoriamento Remoto. Companhia Nacional de Abastecimento - CONAB. Brasília - DF. 2005. Disponível em: <http://www.conab.gov.br/conabweb/download/SIGABRASIL/manuais/conceitos_sm.pdf>. Acesso em: 22 out. 2014.

GARCIA, Y. M. Conflitos de uso do solo em APPs na bacia hidrográfica do córrego Barra Seca (Pederneiras/SP) em função da legislação ambiental. Dissertação (Mestrado em Agronomia) Faculdade de Ciências Agronômicas, Universidade Estadual Paulista, Botucatu, 2014.

GIANUCA, K. S.; TAGLIANI, C. R. Análise em um Sistema de Informação Geográfica (SIG) das alterações na paisagem em ambientes adjacentes a plantios de pínus no Distrito do Estreito, município de São José do Norte, Brasil. Revista da Gestão Costeira Integrada, 12 (1):43-55, 2012.

HAGAN, J.E; EASTMAN, J. R.; AUBLE, J. CartaLinx. The Spatial Data Builder. User's Guide. Version 1.0. Clark Labs. Clark University. 201p. 1998.

IBGE. Instituto Brasileiro de Geografia e Estatística. Carta topográfica: folha de Itapeva (SF-22-Z-DV-3). Serviço gráfico do IBGE, 1974. Escala 1:50.000.

NARDINI, R. C. Determinação do Conflito de Uso e Ocupação do Solo em Áreas de Preservação Permanente da Microbacia do Ribeirão Água-Fria, Bofete (SP), Visando a Conservação dos Recursos Hídricos. Dissertação(Mestrado) - Universidade Estadual Paulista, Faculdade de Ciências Agronômicas, Botucatu, 2009. 
PIMENTEL, A. S. et al. Uso da Geotecnologia na Análise Ambiental das APP's Urbanas de Rio Branco - AC. 2012. Disponível em: <http://www.eng2012.org.br/lista-de-artigos? Acesso em: 22 out. 2014.

ROQUE, C. G.; OliVeiRA, I. C. de; FIGUEIREDO, P. P.; BRUM, E. V. P.; CAMARGO, M. F. Georreferenciamento. Revista de Ciências Agro-Ambientais, Alta Floresta, v.4, n.1, 2006, p.87-102.

ROSA, R. Geotecnologias na Geografia Aplicada. Revista Do Departamento de Geografia, 16, p.81-90, 2005. Disponível em: <http://citrus.uspnet.usp.br/rdg/ojs/index.php/rdg/article/view/55/45>. Acesso em: 22 out. 2014. 